\title{
Primary care treatment guidelines for skin infections in Europe: congruence with antimicrobial resistance found in commensal Staphylococcus aureus in the community
}

\author{
Evelien ME van Bijnen ${ }^{*}$, W John Paget ${ }^{1}$, Casper DJ den Heijer ${ }^{2}$, Ellen E Stobberingh ${ }^{2}$, Cathrien A Bruggeman²,
} François $G$ Schellevis ${ }^{1,3}$ and in collaboration with the APRES Study Team

\begin{abstract}
Background: Over 90\% of antibiotics for human use in Europe are prescribed in primary care. We assessed the congruence between primary care treatment guidelines for skin infections and commensal Staphylococcus aureus (S. aureus) antimicrobial resistance levels in community-dwelling persons.

Methods: The prevalence of antimicrobial resistance in S. aureus was analysed by taking nose swabs from healthy primary care patients in nine European countries (total $N=32,032$ ). Primary care treatment guidelines for bacterial skin infections were interpreted with respect to these antimicrobial resistance patterns. First- and second-choice recommendations were assessed and considered congruent if resistance to the antibiotic did not exceed 20\%.

Results: We included primary care treatment guidelines for impetigo, cellulitis, folliculitis and furuncle. Treatment recommendations in all countries were consistent: most of the first-choice recommendations were beta-lactams, both for children and adults. Antimicrobial resistance levels were low, except for penicillin (on average 73\% resistance). Considerable variation in antimicrobial resistance levels was found between countries, with Sweden displaying the lowest levels and Spain the highest. In some countries resistance to penicillin and azithromycin was significantly higher in children (4-17 years) compared with adults.

Conclusions: Most of the first- and second-choice recommendations in the treatment guidelines for skin infections were congruent with commensal S. aureus antimicrobial resistance patterns in the community, except for two recommendations for penicillin. Given the variation in antimicrobial resistance levels between countries, age groups and health care settings, national data regarding antimicrobial resistance in the community should be taken into account when updating or developing primary care treatment guidelines.
\end{abstract}

Keywords: Antibiotic resistance, Treatment guidelines, Primary care, Skin infections

\section{Background}

Antimicrobial resistance (AMR) has become an important public health threat across the globe during recent decades [1-3]. The development of AMR is considered to be mainly driven by antibiotic use: exposure to antibiotics leads to the selection of resistant bacteria in the commensal microbiota [4-6]. An important source of exposure

\footnotetext{
* Correspondence: e.vanbijnen@nivel.nl

${ }^{1}$ Netherlands Institute for Health Services Research (NIVEL), Otterstraat 118-124, Utrecht, The Netherlands

Full list of author information is available at the end of the article
}

is found in primary care as over $90 \%$ of all antibiotics for human medical use in Europe are prescribed in primary care [5,7]. Therefore, several studies have advocated cautious and appropriate prescribing of antibiotics to control the emergence of AMR [1,8]: empirical treatment with antibiotics should only take place if necessary and should ideally include appropriate agents which are effective against the most common pathogenic bacteria [8].

An inappropriate antibiotic treatment will have several effects, in the first place for the patient: the effectiveness of the treatment will be limited. Secondly, unnecessary 
costs will occur for the health care system; and finally, the exposure to antibiotics could lead to a further increase of AMR [1,9,10]. Several studies recommend the use of relevant AMR data when developing or revising primary care treatment guidelines for bacterial infections $[6,8,11]$. However, since previous AMR studies have mainly obtained data from hospitalized populations with higher resistance levels [6], primary care treatment guidelines might benefit by integrating AMR patterns from the community $[12,13]$.

S. aureus is a part of the commensal microbiota mainly manifesting as bacterial skin and soft tissue infections $[14,15]$. The incidence of these infections in primary care is relatively high, especially in children, hereby forming a considerable cause for antibiotic prescriptions $[14,16,17]$. Traditionally, methicillin-resistant S. aureus (MRSA) was confined to hospitals and long-term-care facilities, but in the last decade MRSA infections have also appeared in healthy community-dwelling individuals [18-21]. Several studies have established the importance of commensal microbiota as a natural reservoir of bacterial resistance, from which resistance can be acquired by pathogens $[22,23]$. By focusing on $S$. aureus, our study assessed the congruency of primary care treatment guidelines for skin infections with AMR data from the community, to optimize treatment effectiveness.

\section{Methods}

\section{Study design}

This study was part of the EC-funded APRES study, aimed at establishing the appropriateness of prescribing antibiotics in primary care in Europe, by collecting data on AMR in the community, antibiotic prescription behaviour and treatment guidelines in primary care. Nine countries across Europe participated in APRES, with varying patterns of antibiotic prescription rates [5]: Austria, Belgium, Croatia, France, Hungary, the Netherlands, Spain, Sweden, and the United Kingdom. A detailed overview of the APRES study design and an analysis of the AMR results have been published elsewhere [4,24]. This paper relates the measured AMR patterns in the community to primary care treatment guidelines for skin infections and assesses their congruency.

\section{Study participants and AMR}

In each of the nine countries, national GP networks selected 20 primary care practices representative of their total GP population. From each of these practices 200 nasal swabs from patients visiting the practice for noninfectious reasons were collected [4,24]. Previous studies $[25,26]$ have shown carriage of $S$. aureus to be dynamic and occurring on multiple bodily sites. With the nares being a common site for $S$. aureus we assumed our sample to be representative of all carriage. In order to assess AMR levels in the commensal flora in the community (from which resistance can be acquired by pathogens), we excluded patients with known important risk factors for AMR: antibiotic use or hospitalisation in the past 3 months. Although $S$. aureus is not the sole pathogen causing skin infections, we selected it due to its impact on public health and relatively high nasal carriage rate $[25,26]$. After isolation of $S$. aureus in 8 national laboratories using standardised procedures, we determined in one central laboratory whether the isolates were resistant or susceptible to a range of commonly used antibiotics in primary care, using cut-off points from the Eucast guidelines $[4,27]$.

\section{Treatment guidelines for skin infections}

Coordinators of national GP networks in each participating country supplied the most commonly used and most recent primary care treatment guidelines for bacterial skin infections. With the exception of Croatia, all countries had issued national treatment guidelines for one or more bacterial skin infections. This resulted in a total of 13 national guidelines from 8 European countries (see Additional file 1: Table S1), from which we extracted the prescription recommendations. We focused the analysis on the antibiotic prescription recommendations for four common bacterial skin infections in primary care which are often caused by S. aureus [13]: impetigo, cellulitis, folliculitis and furuncle. We have analysed the treatment recommendations for antibiotic therapy, distinguishing between first-choice recommendations and, if available, second-choice options. Since skin infections are common in children, we assessed the recommendations for children separately if this information was available.

\section{Data analysis}

To assess the treatment guidelines issued on a national level, resistance levels for each antibiotic were aggregated to a national level by dividing the number of resistant $S$. aureus isolates per country by the total number of persons who carried a $S$. aureus. Separate rates were calculated for children (4-17 years old) and adults (18+), since treatment recommendations are often adapted for children. The recommended antibiotics in the treatment guideline were linked to the respective AMR levels in that country. Based on research regarding urinary tract infections, the antibiotic treatment recommendations were considered to be congruent if the resistance to the antibiotic did not exceed $20 \%$ [28]. Carriership of S. aureus is linked to a higher risk of bacterial skin infection [25,29], however, evidence on the relationship between nasal $S$. aureus and pathogenic $S$. aureus isolated from skin infections is lacking. Therefore, in our current comparison we assumed that pathogenic S. aureus related to skin infections shows the same AMR patterns as nasal colonized $S$. aureus. 
Not all antibiotics mentioned in the treatment guidelines were covered on a product level in the resistance testing of our study. When no AMR data for a specific antibiotic was available, we used two expert opinions (a medical microbiologist and pharmacist) to identify a similar antibiotic: e.g. since no clarithromycin resistance was tested we used data of azithromycin resistance (see Additional file 2: Table S2). Recent studies have shown that resistance to similar antibiotics can serve as a reliable indicator for the level of resistance to the original antibiotic [30,31].

\section{Results}

Data were obtained from a total number of 32,206 swabs and in twenty-two percent $(\mathrm{N}=6,956) S$. aureus was present. After excluding patients for whom age was unknown 6037 (87,8\%) adults (aged 18+) and 840 (12,2\%) children (aged 4 to 17 ) were included in our study sample, of which $56 \%$ were female.

\section{Prevalence of resistance}

Table 1 (adults) and Table 2 (children) show the AMR levels of $S$. aureus for five antibiotics per country. The difference in resistance was high: on average, S. aureus showed almost no resistance to oxacillin $(0.4 \%)$ while resistance to penicillin was high (73\%). Resistance to topical antibiotics was low: averaging $0.4 \%$ for mupirocin and $2.8 \%$ for fusidic acid. The level of variation between countries was considerable, especially regarding AMR levels to azithromycin which ranged from $1.5 \%$ in Sweden to $16.9 \%$ in France. Sweden stood out with the lowest AMR levels to all but one antibiotic. For azithromycin and penicillin significant differences between adults and children were found in some countries, with the higher resistance levels found in children.

\section{Recommendations in treatment guidelines}

Some guidelines were not complete in their coverage of all four infections for both adults and children. Since folliculitis and furuncle are related infections, they were often discussed together in guidelines and the same recommendations were applied. Overall, the first-choice recommendations for skin infections were very consistent across Europe. Almost all recommended first-choice antibiotics were of the B-lactam class, mainly flucloxacillin. Austria and Sweden also recommended cephalosporins for impetigo, folliculitis and furuncle; while in the Netherlands macrolides were preferred for cellulitis in children. For the treatment of impetigo, all guidelines recommended to first start treatment with a topical antibiotic (most often fusidic acid). The second-choice recommendations consisted of a wider range of antibiotics. Most countries used the same antibiotic for adults and children, with an adjusted dosage for children.

\section{Congruency of first- and second-choice antibiotics with AMR patterns}

One can assess the congruency of the recommendations with AMR patterns by determining whether the resistance to the antibiotics is $<20 \%$ (Tables 3 and 4) [28]. As previously mentioned low resistance to the topical agents was found in S. aureus, so the topical treatment recommendations were all congruent with AMR in the community.

\section{Adults}

All first choice recommendations for oral treatment were congruent with the AMR patterns. In Austria (for cellulitis and erysipelas) and Spain (for impetigo) a parenteral treatment with penicillin was advised, which was not congruent with the high penicillin resistance rates found in S. aureus. The second-choice antibiotic treatment recommendations were also congruent, with measured resistance levels

Table 1 Resistance rates of S. aureus isolates in nine European countries - adults 18+

\begin{tabular}{|c|c|c|c|c|c|c|c|c|c|}
\hline \multirow[b]{2}{*}{ Country } & \multirow[b]{2}{*}{ Swabs } & \multirow[b]{2}{*}{$\begin{array}{l}\text { Isolates of } \\
\text { S. aureus }\end{array}$} & \multicolumn{7}{|c|}{ Resistance rates $(\%)$ (95\% confidence interval) } \\
\hline & & & Azithromycin & Clindamycin & Erythromycin & Oxacillin & Penicillin & $\begin{array}{l}\text { Fucidic } \\
\text { acid }\end{array}$ & Mupirocin \\
\hline Austria & 3168 & $522(16.5 \%)$ & $12.8^{* *}(6.3-19.4)$ & $11.1(4.9-17.3)$ & $12.6^{* *}(6.1-19.1)$ & $1.5(0-3.9)$ & $64.4(55-73.8)$ & $1.0(0-3.0)$ & $0.2(0-1.1)$ \\
\hline Belgium & 2892 & $552(19.1 \%)$ & $16.3(9.1-23.5)$ & $14.4(7.5-21.3)$ & $16.3(9.1-23.5)$ & $2.2(0-5.1)$ & $72.5(63.7-81.3)$ & $3.4(0-7.0)$ & $0.4(0-1.6)$ \\
\hline Croatia & 3380 & $601(17.8 \%)$ & $5.8(1.2-10.4)$ & $5.5(1-10)$ & $5.8(1.2-10.4)$ & $2.3(0-5.2)$ & $75.4^{* *}(67-83.8)$ & $0.2(0-1.1)$ & $0.7(0-2.3)$ \\
\hline France & 3536 & 777 (22.0\%) & $17.5(10.1-25.0)$ & $14.9^{*}(7.9-21.9)$ & $17.1(9.7-24.5)$ & $1.8(0-4.4)$ & $74.4(65.8-83)$ & $4.0(0.2-7.8)$ & $0.1(0-0.7)$ \\
\hline Hungary & 2883 & 359 (12.5\%) & $10.3^{* *}(4.3-16.3)$ & $10.3^{* *}(4.3-16.3)$ & $10.3^{* *}(4.3-16.3)$ & $1.9(0-4.6)$ & $71.0^{* *}(62.1-79.9)$ & $0.3(0-1.4)$ & $0.3(0-1.4)$ \\
\hline NL & 3491 & 947 (27.1\%) & $6.9(1.9-11.9)$ & $5.2(0.8-9.6)$ & $5.5(1.0-10.0)$ & $1.0(0-3.0)$ & $68.4(59.3-77.5)$ & $5.2(0.8-9.6)$ & 0 \\
\hline Spain & 3563 & $620(17.5 \%)$ & $11.5(5.3-17.8)$ & $9.5(3.8-15.2)$ & $11.0(4.9-17.1)$ & $1.3(0-3.5)$ & $86.0^{*}(79.2-92.8)$ & $1.1(0-3.1)$ & $1.6(0-4.1)$ \\
\hline Sweden & 2859 & 846 (29.6\%) & $1.3(0-3.5)$ & $11.8(5.5-18.1)$ & $13.0(6.4-19.6)$ & 0 & $64.3^{*}(54.9-73.7)$ & $1.9(0-4.6)$ & 0 \\
\hline UK & 3152 & 811 (25.7\%) & $8.6(3.1-14.1)$ & $7.5(2.3-12.7)$ & $8.9(3.3-14.5)$ & $1.6(0-4.1)$ & $73.4(64.7-82.1)$ & $7.8(2.5-13.1)$ & 0 \\
\hline
\end{tabular}

**Significant difference with children under $\mathrm{p}<0.05$.

*Significant difference with children under $p<0.1$. 
Table 2 Resistance rates of S. aureus isolates in nine European countries - children $<18$

\begin{tabular}{|c|c|c|c|c|c|c|c|c|c|}
\hline \multirow[b]{2}{*}{ Country } & \multirow[b]{2}{*}{ Swabs } & \multirow[b]{2}{*}{$\begin{array}{l}\text { Isolates of } \\
\text { S. aureus }\end{array}$} & \multicolumn{7}{|c|}{ Resistance rates (\%) (95\% confidence intervals) } \\
\hline & & & Azithromycin & Clindamycin & Erythromycin & Oxacillin & Penicillin & $\begin{array}{l}\text { Fucidic } \\
\text { acid }\end{array}$ & Mupirocin \\
\hline Austria & 111 & $23(20.7 \%)$ & $30.4^{* *}(21.4-39.4)$ & $13.0(6.4-19.6)$ & $30.4^{* *}(21.4-39.4)$ & 0 & $73.9(65.3-82.5)$ & $4.3(0.3-8.3)$ & 0 \\
\hline Belgium & 101 & $30(22.9 \%)$ & $16.7(9.4-24)$ & $16.6(9.3-23.9)$ & $16.6(9.3-23.9)$ & 0 & $63.3(53.9-72.7)$ & 0 & 0 \\
\hline Croatia & 562 & $152(27.0 \%)$ & $5.3(0.9-9.7)$ & $4.6(0.5-8.7)$ & $5.3(0.9-9.7)$ & $0.7(0-2.3)$ & $88.2^{* *}(81.9-94.5)$ & 0 & 0 \\
\hline France & 309 & $94(30.4 \%)$ & $11.7(5.4-18.0)$ & $8.5(3.0-14.0)$ & 10.6 (4.6-16.6) & $1.1(0-3.1)$ & $79.8(71.9-87.7)$ & $2.1(0-4.9)$ & 0 \\
\hline Hungary & 930 & 171 (18.4\%) & $16.4^{* *}(9.1-23.7)$ & $16.4(9.1-23.7)$ & $16.4(9.1-23.7)$ & $0.6(0-2.1)$ & $86.0^{* *}(79.2-92.8)$ & 0 & 0 \\
\hline NL & 323 & 119 (36.8\%) & $5.9(1.3-10.5)$ & $3.4(0-7)$ & $4.2(0.3-8.1)$ & 0 & $73.1(64.4-81.8)$ & $0.5(0-1.9)$ & 0 \\
\hline Spain & 427 & 146 (34.4\%) & $12.3(5.9-18.7)$ & $10.3(4.3-16.3)$ & $12.3(5.9-18.7)$ & $0.7(0-2.3)$ & $91.8^{*}(86.4-97.2)$ & 0 & $3.4(0-7.0)$ \\
\hline Sweden & 345 & 104 (30.1\%) & $2.9(0-6.2)$ & $2.9(0-6.2)$ & $2.9(0-6.2)$ & 0 & $73.1^{*}(64.4-81.8)$ & $2.0(0-4.7)$ & 0 \\
\hline \multicolumn{3}{|l|}{ UK } & \multicolumn{7}{|c|}{ No children in study sample due to ethical considerations } \\
\hline
\end{tabular}

**Significant difference with adults under $\mathrm{p}<0.05$.

*Significant difference with adults under $\mathrm{p}<0.1$.

Table 3 Congruency of treatment recommendations for skin infections in adults with national commensal S. aureus resistance rates

\begin{tabular}{|c|c|c|c|c|c|c|}
\hline & Topical AB & Resistance rate* & First choice systemic $A B$ & Resistance rate* & Second choice systemic $A B$ & Resistance rate ${ }^{*}$ \\
\hline \multicolumn{7}{|l|}{ Impetigo } \\
\hline Austria & Fusidic acid & 1.0 & Cephalosporin & No data & Amoxicillin + Clavulanic acid & 1.5 \\
\hline Belgium & Fusidic acid & 3.4 & Flucloxacillin & 2.2 & Clarithromycin & 16.3 \\
\hline France & Fusidic acid & 4.0 & No specific advice & & & \\
\hline Hungary & No guideline & & & & & \\
\hline Netherlands & Fusidic acid & 5.2 & Flucloxacillin & 1.0 & Azithromycin & 6.9 \\
\hline Spain & Mupirocin & 1.6 & Penicillin (IM)/Cloxacillin & 86.0 & Clindamycin & 9.5 \\
\hline & & & & 1.3 & & \\
\hline Sweden & Retapamulin & 0 & Flucloxacillin & 0 & Cefadroxil & No data \\
\hline UK & Fusidic acid & 7.8 & Flucloxacillin & 1.6 & Clarithromycin & 8.9 \\
\hline \multicolumn{7}{|l|}{ Cellulitis } \\
\hline Austria & & & Penicillin (parenteral) & 64.4 & Clindamycin & 11.1 \\
\hline Belgium & & & Flucloxacillin & 2.2 & Clindamycin & 14.4 \\
\hline France & No guideline & & & & & \\
\hline Hungary & No guideline & & & & & \\
\hline Netherlands & & & Flucloxacillin & 1.0 & Claritromycin & 5.5 \\
\hline Spain & & & Cloxacillin & 1.3 & Amoxicillin + Clavulanic acid & 1.3 \\
\hline Sweden & No guideline & & & & & \\
\hline UK & & & Flucloxacillin & 1.6 & Ery/Clarithromycin & 8.9 \\
\hline \multicolumn{7}{|c|}{ Folliculitis and Furuncle } \\
\hline Austria & & & Cephalosporin & No data & Amoxicillin + Clavulanic acid & 1.5 \\
\hline Belgium & No guideline & & & & & \\
\hline France & No guideline & & & & & \\
\hline Hungary & No guideline & & & & & \\
\hline Netherlands & & & Flucloxacillin & 1.0 & No second choice & \\
\hline Spain & & & Cloxacillin & 1.3 & No second choice & \\
\hline Sweden & & & Flucloxacillin & 0 & Cefadroxil & No data \\
\hline UK & & & Flucloxacillin & 1.6 & Ery/Clarithromycin & 8.9 \\
\hline
\end{tabular}

${ }^{*}$ A recommendation is congruent if the resistance rate in S. aureus to that antibiotic is $<20 \%$. Data in bold indicate a resistance rate of $>20 \%$. 
Table 4 Congruency of treatment recommendations for skin infections in children with national commensal S. aureus resistance rates

\begin{tabular}{|c|c|c|c|c|c|c|}
\hline & Topical AB & Resistance rate $^{*}$ & First choice systemic $A B$ & Resistance rate* & Second choice systemic $A B$ & Resistance rate \\
\hline \multicolumn{7}{|l|}{ Impetigo } \\
\hline Austria & Fusidic acid & 4.3 & Cephalosporin & No data & Amoxicillin + clavulanic acid & 0 \\
\hline Belgium & Fusidic acid & 0 & Flucloxacillin & 0 & Clarithromycin & 16.6 \\
\hline France & No guideline & & & & & \\
\hline Hungary & No guideline & & & & & \\
\hline Netherlands & Fusidic acid & 0.5 & Flucloxacillin & 0 & Azithromycin & 5.9 \\
\hline Spain & No guideline & & & & & \\
\hline Sweden & Retapamulin & 0 & Cefadroxil & No data & Flucloxacillin & 0 \\
\hline UK & Fusidic acid & No data & Flucloxacillin & No data & Clarithromycin & No data \\
\hline \multicolumn{7}{|l|}{ Cellulitis } \\
\hline Austria & No guideline & & & & & \\
\hline Belgium & & & Flucloxacillin & 0 & No second choice & \\
\hline France & No guideline & & & & & \\
\hline Hungary & No guideline & & & & & \\
\hline Netherlands & & & Clarithromycin & 4.2 & Azithromycin & 5.9 \\
\hline Spain & No guideline & & & & & \\
\hline Sweden & No guideline & & & & & \\
\hline UK & & & Flucloxacillin & No data & Ery/Clarithromycin & No data \\
\hline \multicolumn{7}{|c|}{ Folliculitis and Furuncle } \\
\hline Austria & & & Cephalosporin & No data & Amoxicillin + Clavulanic acid & 0 \\
\hline Belgium & No guideline & & & & & \\
\hline France & No guideline & & & & & \\
\hline Hungary & No guideline & & & & & \\
\hline Netherlands & No guideline & & & & & \\
\hline Spain & No guideline & & & & & \\
\hline Sweden & No guideline & & & & & \\
\hline UK & & & Flucloxacillin & No data & Ery/Clarithromycin & No data \\
\hline
\end{tabular}

*A recommendation is congruent if the resistance rate in S. aureus to that antibiotic is $<20 \%$.

of $<20 \%$, although for Belgium some recommended antibiotics exceeded $15 \%$ resistance. We found that all recommendations in the Swedish guidelines concerned antibiotics with an AMR level of $0 \%$.

\section{Children}

Only oral therapy was advised for children, in most cases consisting of the same antibiotic that is used for adults (flucloxacillin) but with adjusted dosages. All recommended antibiotics showed a resistance level of $<20 \%$ and were therefore congruent.

\section{Discussion}

This study assessed the congruency of primary care treatment guidelines for bacterial skin infections with nasal AMR levels of $S$. aureus in the community in nine European countries.

\section{Congruency of recommendations}

To assess the congruency of recommendations we used a threshold of 20\%: antibiotics to which S. aureus has resistance rates of $<20 \%$ are considered congruent [28]. Our study showed that most of the first- and second-choice recommendations in the treatment guidelines were congruent with AMR patterns in nasal S. aureus in the community, except for two recommendations for penicillin. Azithromycin was appropriate in the Netherlands, but the relatively high resistance rates in other countries (up to $30 \%$ ) warrant a cautious use of this antibiotic for skin infections.

Given the resistance levels to penicillin in nasal $S$. aureus in the community, our findings suggest that it should not be used as a first- or second-choice antibiotic for $S$. aureus infections in primary care. Most guidelines for skin infections that we assessed were already congruent with 
this finding as they did not recommend the use of penicillin, except for two first-choice recommendations for penicillin in Austria and Spain. The penicillin recommendation for Austria was also used for erysipelas, which is often caused by a streptococcus. The same was true for non-bullous impetigo, for which penicillin was recommended in Spain [32]. Literature regarding AMR levels in streptococci indicates a high susceptibility for penicillin [33], implying these recommendations might be congruent as well in Austria and Spain.

\section{Strengths and limitations}

The strength of our study is the broad scope of the data from nine countries across Europe (North, South, East and West), with a high variation in antibiotic use [5]. Our study is also unique as it assesses the congruency of treatment guidelines for $S$. aureus skin infections in primary care based on the prevalence of antibiotic resistance patterns. The treatment guidelines are issued nationally and have been supplied by experts who are aware of the most frequently used guidelines in their countries. Our study is complete by covering both recommendations for adults and for children.

A previous paper presented information on the dosage and duration of the treatment recommendations. Although the relationship between certain dosage-duration regimes and the development of resistance is not fully clear, it is noteworthy that the treatment guidelines from Sweden recommend higher dosages, while at the same time low AMR was observed [34].

One limitation of our study is that although it tested resistance to a wide range of antibiotics, not all antibiotic recommendations in the guidelines were covered on a one-on-one basis and in some cases we had to use the prevalence of resistance to a similar antibiotic [30,31]. Also, since we excluded patients with current infections or risk factors for AMR (antibiotic use or hospitalisation in the past 3 months), the level of AMR might be an underestimation for the total population in the community. However, given that antibiotic resistance can linger for up to one year [6], we assume our sample to be a good approximation of primary care patients.

Another limitation is the assumption we made that the AMR patterns found in nasal S. aureus are similar to those of pathogenic S. aureus found in SSTIs. To our knowledge, this relationship has not been conclusively studied, and future research might be able to fill this knowledge gap.

Our study is also limited in its choice of pathogen: we focussed on $S$. aureus due to its relatively high prevalence and impact on public health but skin infections can also be caused by a Streptococcus bacteria which may have other AMR patterns and would be relevant to also consider in treatment guidelines. However, since the main pathogen for these skin infections is $S$. aureus we emphasize its importance and recommend that resistance patterns of this pathogen are taken into account when updating or developing treatment guidelines for skin infections. Finally, although our study uses aggregated data, possible regional differences in AMR patterns of pathogens could also be integrated into empiric treatment guidelines.

\section{Implications for primary care}

Most AMR studies present data from non-community settings (e.g. the hospital setting) [34] and there is limited data on antibiotic resistance in the community. The prevalence of resistance of $S$. aureus we found in primary care is lower than the levels reported in hospitals $[4,35]$ and we recommend that recent national AMR data from the community should be taken into account to create more effective and evidence-based treatment guidelines for primary care. In such initiatives other factors affecting evidence-based practice, such as the implementation process or adherence to guidelines, should also be incorporated [36]. Evidencebased guidelines are, however, a first step to control the development of antibiotic resistance.

\section{Conclusions}

Our comparison of primary care treatment guidelines with AMR patterns of commensal S. aureus in the community showed that not all European countries have developed national guidelines for the treatment of common skin infections in primary care and emphasizes the need to develop treatment guidelines in these countries. The firstand second-choice recommendations in the available treatment guidelines proved to be congruent with the national AMR patterns found in nasal colonized $S$. aureus: almost all recommendations concerned antibiotics to which $S$. aureus had low resistance levels (<20\%). Given the high resistance to penicillin that has been demonstrated for commensal S. aureus, we recommend that this antibiotic should not be used in primary care treatment of $S$. aureus related bacterial skin infections. Based on the variation in antimicrobial resistance levels between countries, age groups and health care settings, national data regarding antimicrobial resistance in the community should be taken into account when updating or developing primary care treatment guidelines.

\section{Additional files}

Additional file 1: Table S1. National primary care treatment guidelines included in this study.

Additional file 2: Table S2. Comparison of antibiotics. Some antibiotics recommended in the treatment guidelines have not been tested for resistance in the APRES study. For these, we used the resistance rates of closely related antibiotics.

\section{Competing interests}

The authors declare that they have no competing interests. 


\section{Authors' contributions}

EvB coordinated and carried out data collection and drafted the manuscript; JP coordinated data collection and helped to draft the manuscript, FS conceived of the study and participated in the design and data collection and helped to draft the manuscript; $\mathrm{CdH}$ coordinated and carried out the data collection and reviewed the manuscript; ES and CB coordinated the data collection and reviewed the manuscript. All authors read and approved the final manuscript.

\section{Acknowledgements}

Thanks to Rolf Wolters, a medical student who did an internship at NIVEL and worked on the treatment guidelines.

We thank the APRES study team for their effort in the APRES study: Austria Kathryn Hoffmann, Department of General Practice, Medical University of Vienna, Vienna; Petra Apfalter. Institute of Hygiene, Microbiology and Tropical Medicine, Elisabethinen Hospital, Linz Belgium Herman Goossens and Greet leven, Laboratory of Medical Microbiology, Vaccine and Infectious Disease Institute, University of Antwerp, Antwerp; Stefaan Bartholomeeusen, Department of General Practice, Catholic University of Leuven, Leuven Croatia Milica Katic, Department of Family Medicine, University of Zagreb, Zagreb; Ana Budimir, Department of Clinical and Molecular Microbiology, University Hospital Centre Zagreb, Zagreb France Gilles Hebbrecht, Department of Medical Information, French Society of General Practice, Issy-les-Moulineaux Hungary László Kolozsvári, Department of Family and Occupational Medicine, University of Debrecen, Debrecen; Jozsef Konya, Department of Medical Microbiology, University of Debrecen, Debrecen Sweden Sigvard Mölstad, Department of Clinical Sciences, Lund University, Malmö; Andreas Matussek, Department of Laboratory Services, Ryhov County Hospital, Jönköping Spain Bonaventura Bolibar, Institut Universitari d'Investigació en Atenció Primària Jordi Gol, Barcelona; Elisabet Grenzner, Laboratori Clínic l'Hospitalet. Institut Català de la Salut Metropolitana Sud, I'Hospitalet The Netherlands Joke Korevaar, NIVEL, The Netherlands Institute for Health Services Research, Utrecht UK Mike Pringle, Division of Primary Care, University of Nottingham, Nottingham; Douglas Fleming, Birmingham Research Unit, Royal College of General Practitioners, Birmingham; Andrew Lovering, Department of Medical Microbiology, North Bristol NHS Trust, Bristol. We thank all laboratory personnel, participating GPs and their patients. Without their help this study could not have been conducted. Special thanks to the primary care researchers who provided the guidelines for this manuscript in each country: Austria Kathryn Hoffmann Belgium Stefaan Bartholomeeusen Croatia Dragan Soldo, Marija Botica France Gilles Hebbrecht Hungary Laszlo Kolozsvari Sweden Sigvard Mölstad Spain Boni Bolibar, Albert Boada UK Hayley Durnall.

\section{Funding}

This work was supported by funding from the European Commission - DG Research within its $7^{\text {th }}$ Framework Program [Grant Agreement 223083].

\section{Author details}

${ }^{1}$ Netherlands Institute for Health Services Research (NIVEL), Otterstraat 118-124, Utrecht, The Netherlands. 'Department of Medical Microbiology/ School for Public Health and Primary Care (CAPHRI), Maastricht University Medical Centre, P. Debyelaan 25, Maastricht, The Netherlands. ${ }^{3}$ Department of General Practice and Elderly Care Medicine/EMGO Institute for Health and Care Research, VU University Medical Centre, De Boelelaan 1117, Amsterdam, The Netherlands.

Received: 1 May 2014 Accepted: 10 October 2014

Published online: 25 October 2014

\section{References}

1. European Commission: Staff working paper of the services of the Commission on antimicrobial resistance. http://ec.europa.eu/food/food/ biosafety/salmonella/antimicrobial_resistance.pdf Accessed 8 August 2014

2. European Centre for Disease Prevention and Control (ECDC): Annual epidemiological report. http://www.ecdc.europa.eu/en/publications/ Publications/1111_SUR_Annual_Epidemiological_Report_ on_Communicable_Diseases in_Europe.pdf Accessed 8 August 2014.

3. European Academies Science Advisory Counsil (EASAC): Tackling antibacterial resistance. http://www.easac.eu/fileadmin/PDF_s/ reports_statements/Tackling.pdf Accessed 8 August 2014
4. Den Heijer CDJ, Van Bijnen EME, Paget WJ, Pringle M, Goossens $H$, Bruggeman CA, Schellevis FG, Stobberingh EE, APRES Study Team: Prevalence and resistance of commensal Staphylococcus aureus, including meticillin-resistant Staphylococcus aureus: a European cross-sectional study. Lancet Infect Dis 2013, 13:409-415.

5. Goossens H, Ferech M, Vander Stichele SR, Elseviers M, ESAC Project Group: Outpatient antibiotic use in Europe and association with resistance: a cross-national database study. Lancet 2005, 365:579-587.

6. Costelloe C, Metcalfe C, Lovering A, Mant D, Hay AD: Effect of antibiotic prescribing in primary care on antimicrobial resistance in individual patients: systematic review and meta-analysis. BMJ 2010, 340:c2096.

7. Muller A, Coenen S, Monnet DL, Goossens H, ESAC Project Group: European Surveillance of Antimicrobial Consumption (ESAC): outpatient antibiotic use in Europe, 1998-2005. Euro Surveill 2007, 12(41):pi=3284.

8. Carrie AG, Zhanel GG: Antibacterial use in community practice: assessing quantity, indications and appropriateness, and relationship to the development of antibacterial resistance. Drugs 1999, 57:871-881.

9. Zetola N, Francis JS, Nuermberger EL, Bishai WR: Community-acquired meticillin-resistant Staphylococcus aureus: an emerging threat. Lancet Infect Dis 2005, 5:275-286.

10. Cosgrove SE, Carmeli Y: The impact of antimicrobial resistance on health and economic outcomes. Clin Infect Dis 2003, 36:1433-1437.

11. Infectious diseases society of America: Combating antimicrobial resistance: policy recommendations to save lives. Clin Infect Dis 2011, 52(suppl 5):S397-S428.

12. Kronenberg A, Koenig S, Droz S, Mühlemann K: Active surveillance of antibiotic resistance prevalence in urinary tract and skin infections in the outpatient setting. Clin Microbiol Infect 2011, 17:1845-1851.

13. Van Bijnen EME, Paget J, Den Heijer CDJ, Stobberingh EE, Bruggeman CA, Schellevis FG, in collaboration with the APRES study team: Evidence-based primary care treatment guidelines for skin infections in Europe: a comparative analysis. Eur J Gen Pract 2014. In press.

14. Fleming DM, Elliot AJ: Skin infections and antibiotic prescribing: a comparison of surveillance and prescribing data. Br J Gen Pract 2007 57:569-573

15. May L, Porter C, Tribble D, Armstrong A, Mostafa M, Riddle M: Self-reported incidence of skin and soft tissue infections among deployed US military. Travel Med Infect Dis 2011, 9:213-220.

16. Miller LG, Kaplan SL: Staphylococcus aureus: a community pathogen. Infect Dis Clin North Am 2009, 23:35-52.

17. Ray GT, Suaya JA, Baxter R: Incidence, microbiology, and patient characteristics of skin and soft-tissue infections in a U.S. population: a retrospective population-based study. BMC Infect Dis 2013, 13:252-262.

18. Carleton HA, An Diep B, Charlebois ED, Sensabaugh GF, PerdreauRemington F: Community-adapted methicillin-resistant Staphylococcus aureus: population dynamics of an expanding community reservoir of MRSA. J Infect Dis 2004, 190:1730-1738.

19. Kluytmans-VandenBergh MFQ, Kluytmans JAJW: Community-acquired methicillin-resistant Staphylococcus aureus: current perspectives. Clin Microbiol Infect 2006, 12(Suppl 1):9-15.

20. Salgado CD, Farr BM, Calfee DP: Community-acquired methicillin-resistant Staphylococcus aureus: a meta-analysis of prevalence and risk factors. Clin Infect Dis 2003, 36:131-139.

21. Skov RL, Jensen KS: Community-associated meticillin-resistant Staphylococcus aureus as a cause of hospital-acquired infections. $J$ Hosp Infect 2009, 73:364-370.

22. Sommer MOA, Church GM, Dantas G: The human microbiome harbors a diverse reservoir of antibiotic resistance genes. Virulence 2010, 4:299-303.

23. De Lastours $V$, Chau F, Tubach F, Pasquet B, Ruppé E, Fantin B: Independent behavior of commensal flora for carriage of fluoroquinolone-resistant bacteria in patients at admission. Antimicrob Agents Chemother 2010, 54:5193-5200.

24. Van Bijnen EME, Den Heijer CDJ, Paget WJ, Stobberingh EE, Verheij RA, Bruggeman CA, Pringle M, Goossens H, Schellevis FG: The appropriateness of prescribing antibiotics in the community in Europe: study design. BMC Infect Dis 2011, 11:293

25. Wertheim HF, Melles DC, Vos MC, Van Leeuwen W, Van Belkum A, Verbrugh HA, Nouwen JL: The role of nasal carriage in Staphylococcus aureus infections. Lancet Infect Dis 2005, 5:751-762.

26. Miller LG, Eells SJ, Taylor AR, David MZ, Ortiz N, Zychowski D, Kumar N, Cruz D, Boyle-Vavra S, Daum RS: Staphylococcus aureus colonization among 
household contacts of patients with skin infections: risk factors, strain discordance, and complex ecology. Clin Infect Dis 2012, 54(11):1523-1535.

27. European Committee on Antimicrobial Susceptibility Testing: EUCAST

Definitive Document E.DEF 3.1, June 2000: Determination of minimum inhibitory concentrations (MICs) of antibacterial agents by agar dilution Clin Microbiol Infect 2000, 6:509-515.

28. Gupta K, Hooton TM, Stamm WE: Increasing antimicrobial resistance and the management of uncomplicated community-acquired urinary tract infections. Ann Intern Med 2001, 135:41-50.

29. Kluytmans J, Van Belkum A, Verbrugh H: Nasal carriage of Staphylococcus aureus: epidemiology, underlying mechanisms, and associated risks. Clin Microbiol Rev 1997, 10(3):505-520.

30. Kahlmeter G, Menday P: Cross-resistance and associated resistance in 2478 Escherichia coli isolates from the Pan-European ECO.SENS Project surveying the antimicrobial susceptibility of pathogens from uncomplicated urinary tract infections. J Antimicrob Chemother 2003, 52:128-131.

31. Beerepoot MA, Ter Riet G, Nys S, van der Wal WM, De Borgie CA, De Reijke TM, Prins JM, Koeijers J, Verbon A, Stobberingh E, Geerlings SE: Lactobacilli vs antibiotics to prevent urinary tract infections: a randomized, double-blind, noninferiority trial in postmenopausal women. Arch Intern Med 2012, 172:704-712.

32. Bernard P: Management of common bacterial infections of the skin. Curr Opin Infect Dis 2008, 21:122-128.

33. Albrich WC, Monnet DL, Harbarth S: Antibiotic selection presssure and resistance in Streptococcus pneumoniae and Streptococcus pyogenes. Emerg Infect Dis 2004, 10:514-517.

34. El Moussaoui R, De Borgie CAJM, Van den Broek P, Hustinx WN, Bresser P, Van den Berk GE, Poley JW, van den Berg B, Krouwels FH, Bonten MJ, Weenink C, Bossuyt PM, Speelman P, Opmeer BC, Prins JM: Effectiveness of discontinuing antibiotic treatment after three days versus eight days in mild to moderate-severe community acquired pneumonia: randomised, double blind study. BMJ 2006, 332:1355-1361.

35. Antimicrobial resistance surveillance in Europe. http://www.ecdc.europa. eu/en/publications/Publications/antimicrobial-resistance-surveillanceeurope-2011.pdf Accessed 8 August 2014.

36. Grol R, Wensing M: What drives change? Barriers to and incentives for achieving evidence-based practice. Med J Aust 2004, 180(Suppl):S57-S60.

doi:10.1186/s12875-014-0175-8

Cite this article as: van Bijnen et al:: Primary care treatment guidelines for skin infections in Europe: congruence with antimicrobial resistance found in commensal Staphylococcus aureus in the community. BMC Family Practice 2014 15:175.

\section{Submit your next manuscript to BioMed Central and take full advantage of:}

- Convenient online submission

- Thorough peer review

- No space constraints or color figure charges

- Immediate publication on acceptance

- Inclusion in PubMed, CAS, Scopus and Google Scholar

- Research which is freely available for redistribution 